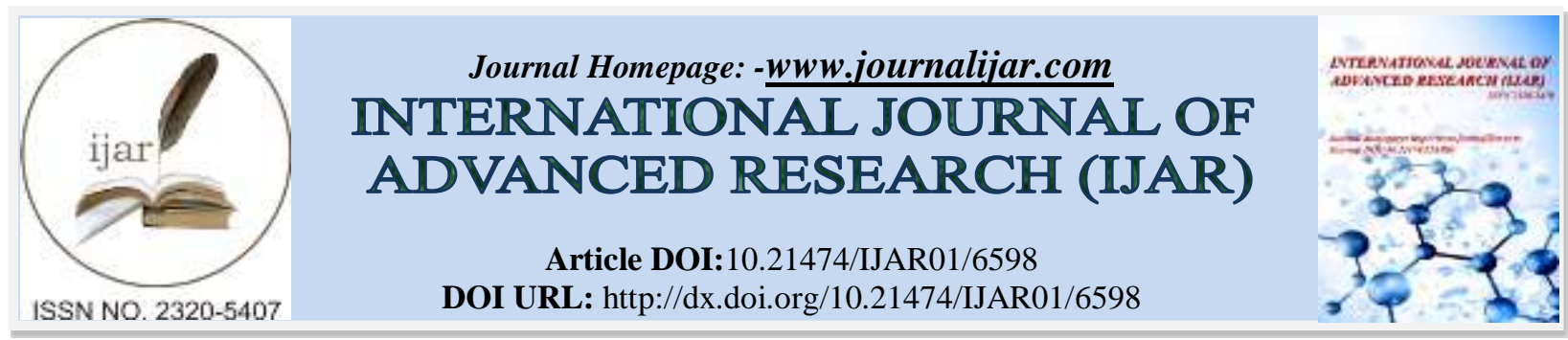

RESEARCH ARTICLE

\title{
LEVEL OF EDUCATION EFFECTS ORGANIZATIONAL ROLE STRESS AMONGST DUAL CAREER COUPLES.
}

\author{
Deepak Kumar.
}

Assistant Professor, JCD Institute of Business Management, SIRSA.

\begin{abstract}
Manuscript Info
Manuscript History

Received: 20 December 2017

Final Accepted: 22 January 2018

Published: February 2018

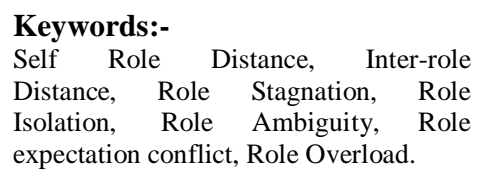

Keywords:-

Distance, Role Stannation, Role

Isolation, Role Ambiguity, Role

expectation conflict, Role Overload.
\end{abstract}

\begin{abstract}
The present paper aims to know the various dimensions of the Organisational Role stress and to find out education based difference in stress level of employees. In the present study a sample of 180 employees were selected from different industries. The present paper successfully highlighted few aspects of the Role Stress among employees. Employees having highest qualification facing maximum organizational role stress. Second most stressed group is employees belonging to Post Graduate and least stressed employees are in the category of senior secondary or lower educational qualification. Highly qualified employees experiences higher level of stress than having lower qualification.
\end{abstract}

Copy Right, IJAR, 2018,. All rights reserved.

\section{Introduction:-}

Stress related to work "is the response people may have when presented with work demands and pressures that are not matched to their knowledge and abilities and which challenge their ability to cope". Stress might be resultant by a number of diverse factors known as stressors. Actually, it leads to complex association of large number of system of interrelated stressors. It is highly useful to make a proper demarcation between stressful work conditions and stress related factors from an individual's reactions. These strains might be caused by a number of factors belonging to mental, physiological, physical and emotional. Occupational stress can arise from a condition when there is a discrepancy between the demands of the workplace and an employees' capability to fulfill these demands. Nevertheless, a stressor may lead to physiological reaction that can strain an employee physically as well as mentally. A variety of factors are responsible for workplace stress. These factors may include tremendous workload, isolation and alienation, extensive working hours, toxic and hazardous working conditions, dearth of autonomy and power, hard and hostile relationships among colleagues and employers, bullying by management and stereotyping, harassment and threat and lack of opportunities and scope for advancement in one's career and professional life.

Work stress is generally elaborated and discussed with the help of two contrasting theoretical models i.e. Model 1: Demand control model and Model 2: Effort reward imbalance model. First model i.e. demand control model expresses stress as combination of demand and control situation at work place. According to this theory, work stress is resultant of a distinct work profile. The theory is more concerned with high demand at work place accompanied with low control over work and working environment. Stress may arise when an employee faces excessive job demand (high expectations and responsibilities) and simultaneously low control over job constructs. Second model is based on the work contract. According to effort- reward model, stress is an outcome of high efforts reciprocated 
by inappropriate or in equivalent rewards in terms of salary, promotion, job security and esteem. It implies that an employee may experience stress if one does not get rewards as per his or her efforts or performance.

\section{Literature Review:-}

Abundant researches are available that seeks to discuss various dimensions and paradigm of organizational role stress. The indirect and hidden cost of work related stress is very high. At individual level, role stress may result into amplified morbidity and mortality (Mark et al, 2003). Globalization and liberalization has resulted into dramatic shift at work place. Rapidly changing work place scene has increased the expectations from the workforce to optimize output and to enhance competitiveness of the firm. It forces workers to execute multiple tasks in the work station. Employees are in constant pressure to be updated with ever dynamic technologies (Quick, 1997). The cumulative effect of these pressures has been found to influence work strain. A comprehensive research conducted in UK stated that the bulk of the employees were discontented with the organizational climate which makes them to work overtime. The organizational culture which makes employee unwillingly cope up with huge loads while concurrently meeting construction objectives and time bound goals (Townley, 2000). Role stress is highly related with working at workplace. Various paradigms of functioning living have been found to have a link with stress. Further, other tenets of work are quite stressful. These aspects of work are work overload (Sparks and Cooper, 1999) and role based aspects such as requirement of sufficient power, role overload, role ambiguity and role conflict (Burke, 1988). Emsley (2003 studied numerous goals and employees' work assignment related apprehension. The researcher found that work associated tension is positively related with multiple goals of manager. Further, performance deteriorates as employees follow different goals and the association seems to be non-linear. A set of researchers have explored stress among employees working in Multi National Companies. Manshor et al (2003) investigated various sources of job-related anxiety among managers working in MNCs of Malaysia. They reported that workload, working condition, and affiliation at office were the major challenges for the managers in Malaysian MNCs and these factors result into anxiety at office. The paper tends to discusses variations caused in ten different constructs of Organizational Role Stress among employees. The ten constructs are Self Role Distance, Inter-role Distance, Role Stagnation, Role Isolation, Role Ambiguity, Role expectation conflict, Role Overload, Role Erosion, Resource Inadequacy, Personal inadequacy given by Udai Pareek (1993).

\section{Objective Of The Study:-}

The prime objective of the present research is to find out education based description of employees Organizational Role Stress amongst Employees and to study the overall status of different dimensions of Organizational Role Stress amongst employees.

\section{Research Metholodly:-}

The researcher collected the data from Banking, insurance, textiles, education, telecommunication, automobiles etc. A sample Size of 180 employees from different departments was contacted to fill a structured questionnaire. The present study is based upon exploratory-cum-descriptive research design. To explore Organisational Role Stress among employees a structured questionnaire developed by Udai Pareek (1993) consisting of 50 statements has been used. These 50 statements explore the stress level of the employees under ten different dimensions of ORS. Data has been collected using five point scale. Random sampling has been used to collect data from various industries.

\section{Result And Discussion:-}

Table-1.1:- Education Based Description of Dimensions of ORS

\begin{tabular}{|l|c|c|c|c|}
\hline \multicolumn{2}{|c|}{ Dimensions of ORS } & \multicolumn{2}{c|}{ Mean } \\
\cline { 2 - 5 } & $\mathbf{1 2}^{\text {th }}$ & Graduation & PG & Ph.D \\
\hline Inter Role Distance (IRD) & 2.37 & 2.74 & 2.98 & 2.87 \\
\hline Role Stagnation (RS) & 2.40 & 2.83 & 2.81 & 2.72 \\
\hline Role Expectation Conflict (REC) & 2.41 & 2.45 & 2.54 & 2.70 \\
\hline Role Erosion (RE) & 2.24 & 2.40 & 2.22 & 2.74 \\
\hline Role Overload (RO) & 2.53 & 2.51 & 2.34 & 2.60 \\
\hline Role Isolation (RI) & 2.38 & 2.42 & 2.53 & 2.80 \\
\hline Personal Inadequacy (PI) & 2.93 & 2.78 & 2.92 & 2.31 \\
\hline Self Role Distance (SRD) & 2.52 & 2.71 & 2.77 & 2.85 \\
\hline Role Ambiguity (RA) & 2.69 & 2.50 & 2.2 & 2 \\
\hline
\end{tabular}




\begin{tabular}{|l|l|l|l|l|}
\hline Resource Inadequacy (RID) & 2.89 & 2.71 & 2.69 & 2.71 \\
\hline Overall & 2.53 & 2.60 & 2.66 & 2.71 \\
\hline
\end{tabular}

Table-1.1 elucidates educational qualification based mean value of organizational role stress among employees. It is reported that mean value for employees having highest educational qualifications have maximum organizational role stress (mean=2.71). Reasons are depicted in mean value of ten constructs of organizational role stress. Prime reason for such high stress level among category is Inter Role Distance (mean=2.87), Role overload $(m e a n=2.86)$ and role ambiguity (mean=2.85). Naturally as educational qualifications of an employee increases at the same time role expectation from him or her also increases. For example, employer will expect different kind of attitude, behavior, skill set and knowledge from a Post Graduate employee than expected from a simple graduate person. Similar, higher academic credentials may also lead to increased inter role distance. For inference, a doctorate working lady may not align well with domestic work than a senior secondary pass lady. And, thus for doctorate woman, role distance between Professorship and house wife may be more than less educated woman.

Second most stressed group is employees belonging to Post Graduate. Difference of mean between most stressed category and second ranked category is very small. Findings suggest that Inter Role Distance (mean=2.98), Role expectation conflict (mean=2.84) and role stagnation (mean=2.81) contributes maximum to existing stress level for this educational qualification category of employees. The findings are again can be compared to that of $\mathrm{PhD}$ and other higher qualification group..

Least stressed employees are in the category of senior secondary or lower educational qualification (mean=2.53) but mean of another class of education i.e. Graduate (mean=2.60) is also very close to the lowest value. The sequence of stress felt by employees shows an increasing trend with increase in educational qualification.

Statistical significance of such variation among employee of different experience group is discussed in detail in table 1.2 with the help of ANOVA. Experience based variations could be depicted diagrammatically as below. Researcher got a steadily increasing curve while education credentials are plotted against organizational role stress experienced by employees in Indian settings.

Figure- 1:- Education based variations among ORS in employees.

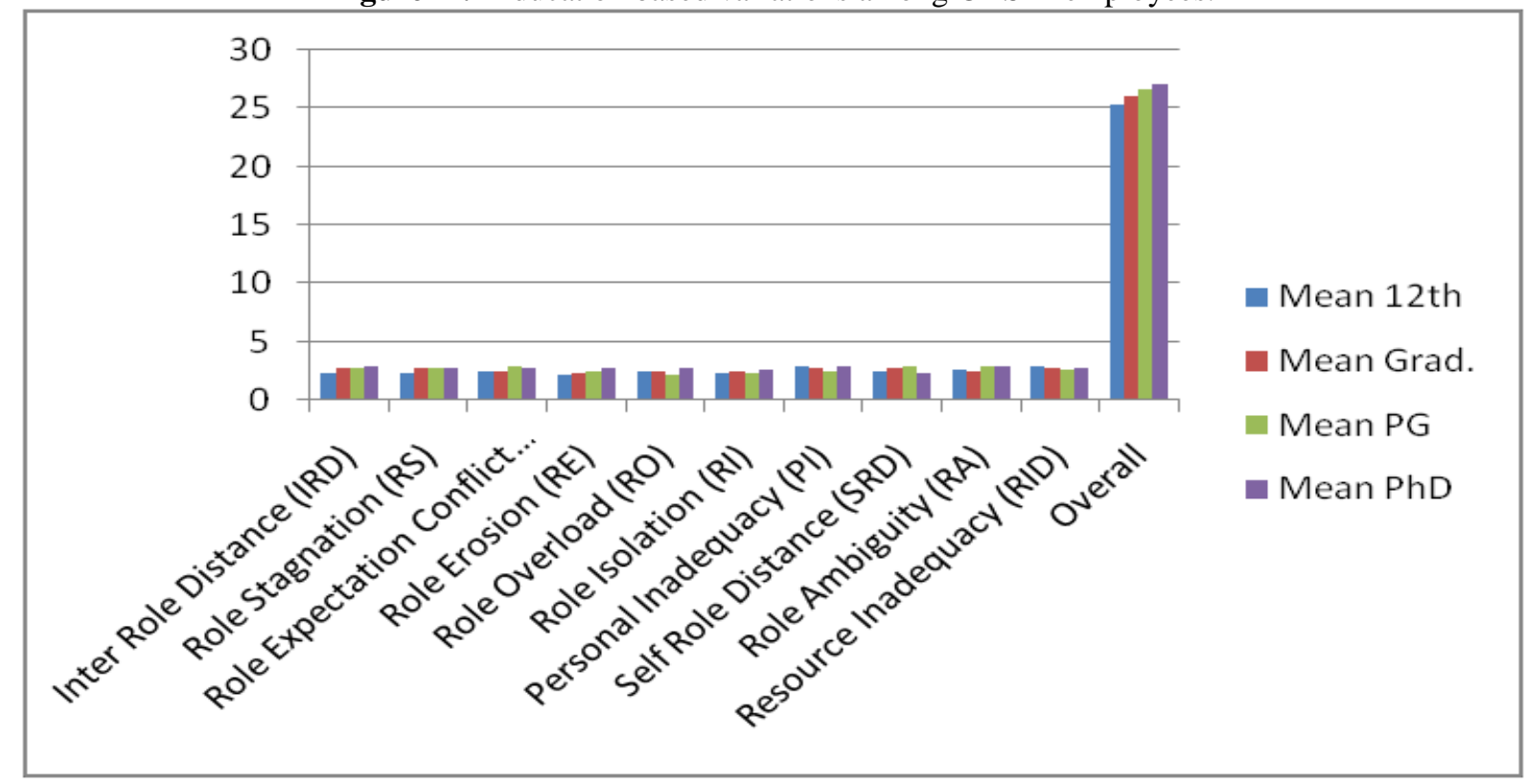


Table-1.2:- Education Based Variations in Organizational Role Stress

\begin{tabular}{|c|c|c|c|}
\hline \multirow[t]{2}{*}{ S. No } & \multirow[t]{2}{*}{ FACTORS } & \multicolumn{2}{|c|}{ Education } \\
\hline & & f-Value & Significance. \\
\hline 1 & Inter Role Distance (IRD) & 2.87 & 0.004 \\
\hline 2 & Role Stagnation (RS) & 3.751 & 0.000 \\
\hline 2 & Role Expectation Conflict (REC) & 0.094 & 0.925 \\
\hline 4 & Role Erosion (RE) & 2.303 & 0.002 \\
\hline 5 & Role Overload (RO) & 3.854 & 0.000 \\
\hline 6 & Role Isolation (RI) & 1.174 & 0.242 \\
\hline 7 & Personal Inadequacy (PI) & 3.281 & 0.001 \\
\hline 8 & Self Role Distance (SRD) & 4.34 & 0.000 \\
\hline 9 & Role Ambiguity (RA) & 2.873 & 0.004 \\
\hline 10 & Resource Inadequacy (RID) & 3.114 & 0.002 \\
\hline & Overall & 3.687 & $\mathbf{0 . 0 0 7}$ \\
\hline
\end{tabular}

Table-1.2 describes result of ANOVA applied to explore statistical significance of differences based on educational qualifications of employees. Overall education based variations come out to be statistical significant as significance value is smaller than .05 at $95 \%$ degree of confidence scale. The findings statistically support the findings of table 1.1. Now it is statistically proved that employees having highest degree experience category feels maximum organizational stress. Stress is being experienced by employees of different education group in the sequence as: highest for $\mathrm{PhD} /$ other higher degree followed by graduate employees then employees having graduate degree and least stress is experienced by employees having studied up to class $12^{\text {th }}$ only. Thus one can easily notice a pattern of steadily increase in stress level with increase in educational qualification for employees in India. As a matter of fact, the difference in mean value of organizational role stress is minute for employees with different educational qualifications.

Seven out of ten constructs of organizational role stress reported significant variations for differently educated employees. The constructs are Inter Role Distance, Role Isolation, Role Overload, Personal Inadequacy, Role Ambiguity, Role Expectation Conflict and Self Role Distance and Resource Inadequacy (value of $\mathrm{p}$ is lesser than .05 for all these constructs at $95 \%$ level of significance). Employees of all educational qualifications are equally stressed for two constructs of organizational role stress. The three paradigms are Role Expectation Conflict and Role Isolation.

\section{Conclusion:-}

Organizational Role Stress has been a permanent challenge for both i.e. for employee and for an organization too. One of the most critical issues that majority of organization faces today is recruitment and retention of qualified employees. Turnover and absenteeism is a major challenge for all sort of organizations. The problem of stress is higher for employees. Thus the study of ORS for employees is of utmost significance for both complementary actors of corporate world. The present paper successfully highlighted few aspects of the Role Stress among employees. Employees having highest qualification facing maximum organizational role stress. Second most stressed group is employees belonging to Post Graduate and least stressed employees are in the category of senior secondary or lower educational qualification.

Highly qualified employee's experiences higher level of stress than having lower qualification. 


\section{References:-}

1. Albuquerque, Z. M., Rao, K., Rao, S., Subbakrishna, D. K., and Prabhu, G. G. (1990), Stress and coping in psychologically distressed and non-distressed students, Indian Journal of Psychological Medicine, 13, 63-70.

2. Alexandros-Stamatios G. A., Matilyn J.D., and Cary L.C., (2003), Occupational Stress, Job satisfaction, and health state in male and female junior hospital doctors in Greece, Journal of Managerial Psychology, 18(6), pp 592-621

3. Burke, R.J., Greenglass, E.R. (2001), Hospital restructuring and nursing staff wellbeing: the role of perceived hospital and union support, Anxiety, Stress and Coping: An International Journal, 14(3), pp 93-115.

4. Banet, Plint and Clifford, (2005), Reducing stress and avoiding burnout: A collection of activities for preschoolers, 11(2), pp. 28-32.

5. Cooper, C. L., Marshall, J. (1976), Occupational sources of stress: a review of the literature relating to coronary heart disease and mental ill health, Journal of occupational psychology, 49(1): 11-28

6. Cooper, C., U. Rout and B. Faragher, (1989), Mental Health, Job Satisfaction, and Job Stress Among General Practitioners, B Medical Journal, 298, pp. 366-370.

7. Emsley, David (2003), Multiple goals and managers' job-related tension and performance, Journal of Managerial Psychology, 18 (4), pp 345-356.

8. Ivancevich, J. and Matteson, M.T., (1987), Stress at Work: A managerial perspective, Glenview, IL: Scott, Foresman.

9. Ivancevich, J. and Matteson, M., (1980), Stress at Work, Glenview, IL: Scott, Foresman

10. Manshor, A. T., Fontaine, R., Choy, Chong Siong, (2003), Occupational stress among managers: a Malaysian survey, Journal of Managerial Psychology, 18(6), pp 622- 628.

11. Midgley, S. (1996), Pressure Points (managing job stress), Journal of People Management, 3(14), pp 3637.

12. Mark, L. F., Jonathan and Gregory, S. K. (2003), Eustress, Distress and Interpretation in Occupational Stress, Journal of Managerial Psychology, 18(7), pp 726-744.

13. Marks, S.R. and MacDemid, S.M. (1996), Multiple roles and the self: a theory of role balance, Journal of Marriage and the Family, 58, pp. 417-432

14. Pareek, U. (1993), Motivating Organisational Roles: Role Efficacy Approach, Jaipur: Rawat Publication.

15. Pareek, U. (1983), Organizational Role Stress Scale, Manual. Ahmedabad: Navina Publication.

16. Pareek, U., (1993), Motivating Organizational Roles: Role Efficacy Approach, Jaipur: Rawat Publication.

17. Pestonjee, D.M, Azeem SM (2001), A study of Organizational Role Stress in relation to Job Burnout among university teachers. IIMA Working papers (Indian institute of management Ahmedabad, Research and Publication Department) 2001.

18. Richard VG, Krieshok ST (1989), Occupational stress, strain, and coping in university faculty, Journal of Vocational Behavior, 34, pp. 117-132.

19. Schabracq, M. J. and Cooper, C. L. (2000), The Changing Nature of Work and Stress, Journal of Managerial Psychology, 15(3), pp 227-42. 